\title{
DICIONÁRIOS \\ EM SALA DE AULA: \\ ANÁLISES DO MATERIAL \\ DE APOIO DESTINADO \\ AO ENSINO MÉDIO \\ DAS ESCOLAS PÚBLICAS \\ DO ESTADO \\ DE SÃO PAULO
}

\section{DICCIONARIOS EN EL AULA: ANÁLISIS DEL MATERIAL DE APOYO DESTINADO A LA ENSEÑANZA SECUNDARIA DE LAS ESCUELAS PÚBLICAS DEL ESTADO DE SÃO PAULO}

DICTIONARIES IN THE CLASSROOM: ANALYZES OF THE STUDENT'S NOTEBOOK PROVIDED TO PUBLIC HIGH SCHOOLS BY THE STATE OF SÃO PAULO

Sabrina de Cássia Martins* Claudia Zavaglia** Universidade Estadual Paulista | campus São José do Rio Preto

RESUMO: A virada do século XX para o século XXI no contexto brasileiro é acompanhada por uma nova leitura sobre o conceito de formação linguística do indivíduo. Nesse cenário, a atenção volta-se para as tecnologias que atuam como instrumentos de apropriação das línguas, bem como para a sua eficácia. O presente trabalho segue uma orientação lexicográfica a partir de uma perspectiva multidisciplinar e tem como objetivo provocar a reflexão sobre o uso do dicionário em sala de aula. Expomos um breve panorama sobre as políticas linguísticas no Brasil (BAGNO; RANGEL, 2005; TORQUATO, 2010; OLIVEIRA, 2013), em especial as tentativas de reinserção do dicionário no cotidiano do cidadão brasileiro (BOLZAN; DURÃO, 2011; KRIEGER, 2005; 2012;

\footnotetext{
* Doutora pelo Programa de Pós-graduação em Estudos Linguísticos da Universidade Estadual Paulista Júlio de Mesquita Filho - UNESP - Campus de São José do Rio Preto - SP - IBILCE. Atualmente, desenvolve seu pós-doutorado e atua como professorasubstitutadoDepartamentode Letras Modernasna mesmainstituição. E-mail:sabrina.martins@unesp.br.

** É livre-docente em Lexicografia e Lexicologia desde 2009 . Atualmente é professora associada da Universidade Estadual Paulista Júlio de Mesquita Filho - UNeSP - Câmpus de São José do Rio Preto - SP - IBILCE, atuando desde 2003 na Pósgraduaçãoem Estudos Linguísticosnalinha Lexicologiae Lexicografia.E-mail:claudia.zavaglia@unesp.br.
} 
PONTES; SANTIAGO, 2009; PONTES, 2009, 2014). Em segundo lugar, analisamos a forma como isso vem sendo estimulado pelo Estado no dia a dia em sala de aula. Para tanto, tomamos como base o material de apoio para o Ensino Médio fornecido para as escolas públicas pela Secretaria de Educação do Estado de São Paulo. Apesar dos esforços tanto por parte do Governo Federal quanto do Estado de São Paulo para nortear a aprendizagem, observa-se a falta de direcionamento da manipulação de dicionários, glossários e enciclopédias, além da falta de estímulo quanto ao uso das obras de referência em sala de aula.

PALAVRAS-CHAVE: Ensino/aprendizagem. Língua materna. Dicionário. Sala de aula.

RESUMEN: El cambio del siglo XX al siglo XXI, en el contexto brasileño, va acompañado de una nueva lectura sobre el concepto de formación lingüística del individuo. En este escenario, la atención se centra tanto en las tecnologías que actúan como instrumentos para la apropiación de las lenguas, como en su eficacia. El presente trabajo sigue una orientación lexicográfica desde una perspectiva multidisciplinaria y tiene como objetivo provocar una reflexión sobre el uso del diccionario en el aula. En primer lugar, presentamos un breve panorama de las políticas lingüísticas en Brasil (BAGNO; RANGEL, 2005; TORQUATO, 2010; OLIVEIRA, 2013) y, en particular, los intentos de reintegrar el diccionario a la vida cotidiana de los ciudadanos brasileños (BOLZAN; DURÃO, 2011; KRIEGER, 2005, 2012; PONTES; SANTIAGO, 2009; PONTES, 2009, 2014). En segundo lugar, analizamos la forma como eso viene siendo estimulado por el Estado en la cotidianidad del salón de clase. Para ello, tomamos como base el material de apoyo de nivel secundario provisto a las escuelas públicas por el Departamento de Educación del Estado de São Paulo. A pesar de los esfuerzos, tanto por parte del Gobierno Federal como del Gobierno del Estado de São Paulo, para guiar el aprendizaje, se observa una falta de direccionamiento en la manipulación de diccionarios, glosarios y enciclopedias, además de la falta de estímulo hacia el uso de obras como consulta en el aula.

PALABRAS CLAVE: Enseñanza/aprendizaje. Lengua materna. Diccionario. Aula.

ABSTRACT: The passage from the $20^{\text {th }}$ to the $21^{\text {st }}$ century in the Brazilian context is accompanied by a new interpretation of language background. In this scenario, attention is focused on technologies that act as language appropriation instruments as well as on their effectiveness. This work follows a lexicographic orientation from a multidisciplinary perspective, and aims to instigate the reflection on dictionary use in the classroom. Firstly, we present a brief overview about the Brazilian language policies (BAGNO; RANGEL, 2005; TORQUATO, 2010; OLIVEIRA, 2013), especially those of dictionary reintegration in the daily life of Brazilian citizens (BOLZAN; DURÃO, 2011; KRIEGER, 2005; 2012; PONTES; SANTIAGO, 2009; PONTES, 2009, 2014). Secondly, we examine how dictionary use has been stimulated in Portuguese language classrooms of public high schools. Therefore, we analyse the High School student's notebook provided to public schools by the Department of Education of the State of São Paulo. Despite all the efforts by both the Federal Government and the São Paulo State Government to guide learning process, there is a lack of orientation and encouragement to dictionaries, glossaries and encyclopedias use in the classroom.

KEYWORDS: Teaching/learning. Mother tongue. Dictionary. Classroom.

\section{INTRODUÇÃO}

O dicionário, ao lado da gramática, é um dos pilares do saber metalinguístico de uma língua, ambos produtos do seu processo de descrição (AUROUX, 1992). Desde o princípio, as obras lexicográficas constituíram-se como artefatos culturais e sua produção sempre esteve relacionada à satisfação das necessidades do ser humano (FUERTES-OLIVERA; TARP, 2008), desempenhando um papel social bem definido e essencial para toda e qualquer comunidade, o que inclui a interpretação de uma cultura e a compreensão de seu progresso (JACKSON, 2002).

Como relato linguístico, o dicionário é responsável por memorizar o conjunto lexical de uma língua, consagrando a expressão verbal de uma cultura e o progresso de uma sociedade, permitindo sua interpretação por outros povos. Assim como a sociedade que o produz, também o dicionário modifica-se no decorrer do tempo. Como registro de uma língua, tal obra descreve os efeitos das mudanças da sociedade na atualização do léxico. A consulta ao dicionário, por outro lado, revela a relação de correspondência entre objetos do mundo. Tal fato aponta para o seu papel de intermediar simbolicamente a determinação dos significados e apoiar a construção da rede de conhecimento linguístico (COROA, 2011). 
No decorrer dos séculos, a prática de elaboração de dicionários assume diferentes propósitos, refletindo as transformações sociais. Assim, a partir do século XVIII, o dicionário, entendido como um instrumento de autoaprendizagem, transita entre a função cultural e a educadora, quando já no século XX, devido ao seu caráter prescritivo e normativo, passa a ter a função escolar (BÉJOINT, 2010)

A virada do milênio traz consigo o caráter e o rigor científico necessários para o papel do dicionário como representante de uma língua, elevando a Lexicografia ao patamar de ciência. Sua preocupação concentra-se em demonstrar o uso a partir de contextos autênticos. Nesse aspecto, identificamos o referencial teórico resgatado dos estudos da linguagem e retomamos sua parceria com a gramática para o ensino-aprendizagem de línguas. A preocupação quanto à eficácia do dicionário demonstra-se pela ascensão da Lexicografia Pedagógica, entendida como um ramo da Lexicografia que se ocupa 1. da análise das potencialidades pedagógicas dos dicionários, 2. da investigação do uso de tais obras por estudantes e professores e 3. da elaboração de dicionários pedagógicos, tendo como objetivo maior promover o dicionário como uma ferramenta que proporciona o acesso ao conhecimento novo e o aperfeiçoamento das habilidades linguísticas.

Contudo, considerando a Lexicografia como disciplina que integra os vieses teórico e prático, a realidade atual demonstra o descompasso entre o conhecimento produzido pela academia e a finalidade última do objeto dicionário, isto é, a apropriação do saber linguístico pelo usuário da obra. Isso significa que, embora os estudos contemporâneos em Lexicografia assumam como base para a elaboração das obras lexicográficas as necessidades do usuário, este último sente-se inseguro e desmotivado quanto ao uso do dicionário.

O presente trabalho segue uma orientação lexicográfica a partir de uma perspectiva multidisciplinar, na medida em que o dicionário assume o papel de instrumento de reflexão sobre a língua e de aquisição de conhecimento. Nesse sentido, partindo da análise do material de apoio voltado ao Ensino Médio das escolas públicas e formulado pela Secretaria de Educação do Governo do Estado de São Paulo, edição 2014-2017, analisamos a forma como o uso do dicionário de língua materna vem sendo estimulado pelo material didático no dia a dia em sala de aula. Para tanto, nas próximas páginas, primeiramente, expomos um breve panorama sobre as políticas linguísticas no Brasil, em especial as tentativas de reinserção do dicionário no cotidiano do cidadão brasileiro. Posteriormente, analisamos o modo como tal missão é estimulada pelo Estado no dia a dia em sala de aula.

\section{POLÍTICAS LINGUÍSTICAS, ENSINO DE LÍNGUA MATERNA E DICIONÁRIOS}

É historicamente comprovado que a imposição da língua é uma forma de domínio cultural, de implantação de poder e supressão de identidade. Também a língua é organizada em sistemas estruturados, cujas assimetrias e dominação refletem aquelas estabelecidas pela sociedade. Como enfatiza Guimarães (2001), o político remete à forma de tomar a palavra. Por conseguinte, o Estado, na tentativa de mediar conflitos e gerenciar as negociações que tenham como tema a relação entre poder e língua, ou entre a língua e seus usos na sociedade, propõe políticas linguísticas.

Calvet (2002, p.145 apud TORQUATO, 2010, p. 7-8) determina que a política linguística envolve [...] "um conjunto de escolhas conscientes referentes às relações entre língua(s) e vida social”, ou seja, propostas elaboradas por indivíduos integrantes de um grupo social, cujo objetivo é estabelecer um vínculo entre língua e sociedade. Oliveira (2013) baseando-se em Calvet (2007), enfatiza que uma política linguística abrange as relações entre as línguas e a sociedade, pois determina "[...] em que língua o Estado funcionará e se relacionará com os cidadãos, em que língua(s) a educação e os serviços culturais serão oferecidos, que variedade de língua será usada, se as outras línguas faladas pelos cidadãos serão reprimidas, reconhecidas ou promovidas".

Louis-Jean Calvet sustenta, nesses dois estudos mencionados, que há duas maneiras de gerir as políticas linguísticas: in vivo, procedendo das práticas sociais, ou in vitro, intervindo sobre elas. Cabe ao Estado executar tais propostas por meio do planejamento linguístico, isto é, o caminho a ser seguido durante a implementação das políticas linguísticas para a sua concretização, mediando as reivindicações e as ações político-identitárias dos indivíduos. 
No contexto latino-americano, segundo o autor supracitado, as línguas são instrumentos de relações de poder herdados do período colonial e utilizados nos períodos posteriores para dominação das línguas locais. Como bem observam Bagno e Rangel (2005), a história da formação da sociedade brasileira demonstra a atuação da língua no processo de dominação cultural, além da tentativa de criar uma imagem de um país monolíngue e, portanto, nacionalmente coeso, harmônico e homogêneo. Tal fato é comprovado pela repressão sofrida pelos habitantes brasileiros no que tange à língua falada ao longo da história. Em um primeiro momento, temos a imposição da língua geral; posteriormente, já no século XVIII, a proibição, por parte da metrópole portuguesa, da utilização da língua geral. Nesses casos, como apontado por Orlandi (1998), predomina a posição de política linguística que tem como princípio a dominação como valor, visto que há a anulação das diferenças e a absorção da cultura do outro.

Entre o final do século XIX e o início do século XX, ocorre a instituição da língua nacional, representante da unidade social brasileira. Nesse período, nasce o conceito de norma culta como sinônimo de norma padrão, tal como o espelho do desejável na interação entre falantes de escolaridade superior completa em situações formais. Como bem sublinha Madeira (2005), durante as primeiras décadas do século XX predominava o sistema de ensino que ignorava as camadas populares, estando baseado no aspecto normativo e discriminatório de toda e qualquer variedade linguística desviante da norma padrão.

Tal cenário se transforma a partir da década de 30, com a Constituição de 1934, que propõe a Lei de Diretrizes e Bases da educação, resultado das manifestações que clamavam pelo fim do ensino discriminatório e excludente. Contudo, no decorrer das décadas posteriores, embora o ensino de língua materna tenha assumido uma concepção de língua nacional como instrumento de comunicação e expressão cultural, trazendo como proposta a inserção de diferentes textos em aula, a prática continuou a adotar a face homogeneizadora da língua. Trata-se de um hábito herdado do início do século passado que concebe a língua como um objeto estático, puro e correto, imortalizado nas obras dos grandes escritores e relatado nos livros de gramática e nos dicionários.

Consequentemente, a concepção de língua abordada em sala de aula continuou sendo aquela portadora de autoridade, capaz de assegurar o sentimento de unidade da sociedade brasileira. Assim, em prol do respeito às regras da desejada norma culta, optou-se por desconsiderar a existência das variantes linguísticas e por ignorar a variação inerente às línguas naturais. A face heterogênea, representada pelas variedades utilizadas nas práticas cotidianas, continuou estigmatizada e desconsiderada nas reflexões linguísticas durante as aulas de português.

Esse panorama permanece estático até o final do século XX. Diante do nível crítico de conhecimento sobre a língua portuguesa por parte da maioria dos brasileiros, admite-se a necessidade de renovação do seu ensino. Durante a segunda metade do século passado, o debate volta-se à inconsistência teórica e à falta de coerência do modelo normativo por não explicar o uso real da língua. Reconhece-se que o papel da escola é o de proporcionar condições para que o aluno conheça outras variedades linguísticas. Nesse contexto, os Parâmetros Curriculares Nacionais (PCNs), lançados no ano 2000, resgatam de modo mais evidente a contribuição dos estudos linguísticos, reflexo da intensa discussão acerca do ensino-aprendizagem de língua materna. Dessa forma, ocorre a transição do foco concentrado na gramática normativa para uma postura que privilegia o texto, sem que para tanto sejam excluídas situações didáticas direcionadas à palavra ou à frase. Uma postura que exige a reavaliação das concepções de linguagem, de língua e até mesmo de ensino de língua materna.

Efetivamente, embora exista o diálogo entre as políticas de ensino e as reflexões teóricas no âmbito dos estudos linguísticos, as mudanças em sala de aula ocorrem em um ritmo bem mais lento, que implica uma transformação do sujeito-aluno, bem como a diluição de uma ideologia linguística impregnada na sociedade. Nesse aspecto, Bagno e Rangel (2005) defendem a articulação entre as demandas sociais, as políticas públicas e a pedagogia da educação em língua materna, de modo a privilegiar a integração de diferentes recursos linguísticos em cada situação comunicativa.

Castilho (2001), por sua vez, ao reconhecer o problema da performance na modalidade escrita, enfatiza que escrever é um trabalho penoso que exige o compromisso com a palavra, ou seja, em dizer algo com coerência e com argumentos. Logo, é preciso possibilitar ao aluno o reconhecimento das características discursivas típicas de cada evento comunicativo para que ele se aproprie do conhecimento em língua materna e esteja apto ao seu uso em todo e qualquer contexto. 
Concernente à presença do dicionário em sala de aula e à sua contribuição para o ensino-aprendizagem de língua materna, embora o objetivo de tais obras de referência seja descrever o léxico de uma língua, durante muito tempo, tal descrição restringiu-se à variedade culta, representada pela literatura de língua portuguesa. Logo, uma realidade distante daquela do aluno comum. Ao longo do século XX, predomina o caráter prescritivo e normativo aliado à sua função escolar (BÉJOINT, 2010). Tal cenário modifica-se apenas no final do século passado, com o crescente avanço da Lexicografia como disciplina e área de estudo. A seguir, discorremos sobre as políticas de inserção das obras lexicográficas no cotidiano do aluno.

\section{O PNLD: DICIONÁRIOS E A APROPRIAÇÃO DA LÍNGUA MATERNA}

Nas últimas décadas, o Governo Nacional, alarmado com os resultados negativos sobre a situação de ensino-aprendizagem de língua materna obtidos através de testes avaliativos, dentre eles a Saeb para os anos finais do Ensino Fundamental e o Enem para os alunos do Ensino Médio (EM), tem destinado maior atenção à formação dos brasileiros. Para tanto, forças-tarefas, tais como o Programa Nacional do Livro Didático (PNLD) foram implementadas para contornar esse cenário. Como ressaltam Durão e Bolzan (2011, p. 183), o programa "[...] além de retomar o valor pedagógico de gramáticas e dicionários, propondo remodelá-los da forma mais próxima possível das situações e demandas do ensino e aprendizagem formais, também induziu à inclusão da consulta a dicionários como objeto de ensino e aprendizagem escolar."

É a partir dos anos 2000 que os dicionários passam a integrar de forma efetiva o PNLD, fato que, segundo Santos e Sousa (2015), estimula a produção de obras para o uso em sala de aula por parte das editoras brasileiras. A princípio, os dicionários são distribuídos de forma individual. Com a reformulação do programa em 2006, duas mudanças ocorrem: 1) a partir desse momento, o objetivo é "equipar as escolas com um número significativo de diferentes títulos de dicionários" (BRASIL, 2006, p. 31, grifo do autor); 2) os dicionários são organizados em acervos distintos, cada um direcionado a um nível de ensino-aprendizagem, obedecendo "a propostas pedagógicas e lexicográficas particulares, voltadas para o aluno de um ou outro desses níveis” (BRASIL, 2006, p. 32).

Por conseguinte, observa-se em tais obras particularidades tanto na macro quanto na microestrutura, sendo respeitadas as características do público ao qual a obra é destinada. O PNLD/2006 define três tipos de obras lexicográficas, todas direcionadas ao Ensino Fundamental. O PNLD/2012, por outro lado, inclui um quarto tipo, destinado ao Ensino Médio (EM). Assim, temos a seguinte distribuição dos dicionários, de acordo com as etapas de ensino: "Tipo 1 - para o $1^{\circ}$ ano do EF; Tipo 2 - para o período entre o $2^{\circ}$ e o $5^{\circ}$ ano do EF; Tipo 3 - para o segundo segmento do EF; Tipo 4 - para o EM." (BRASIL, 2012, p.3). Também em 2006 é lançado o Guia Dicionários em Sala de Aula (BRASIL, 2006), um incentivo para o uso dos dicionários em sala de aula.

Seguramente, como instrumento didático, o valor do dicionário é inegável, visto seu objetivo em descrever o comportamento linguístico, gramatical e pragmático de uma unidade léxica. De acordo com Carstens (1995), o dicionário auxilia o falante a atingir a proficiência em uma língua, o que significa dominá-la quanto à leitura, à escrita, à fala e à compreensão. Logo, justifica-se a atual contemplação de obras lexicográficas pelo PNLD, que entende tais obras, ao lado da gramática, como textos metalinguísticos por excelência.

Contudo, como enfatizado por Krieger $(2005,2012)$, o dicionário ainda é pouco explorado em sala de aula. Tal fato, explica a autora, relaciona-se, por um lado, ao descompasso dos estudos na área, por outro, à falta de segurança e preparo dos professores para utilizálo de forma eficiente em sala. Carstens (1995) elenca uma série de fatores que contribuem para essa situação: 1. ausência nos currículos; 2. disponibilidade de dicionários; 3 . aversão ao uso de dicionários; 4. interferência comunicativa (geralmente na fala, em que não há como interromper a comunicação para fazer uma busca no dicionário); 5. conhecimento sobre os tipos de dicionários; 6. falta de habilidade quanto ao uso de obras de referência por parte dos alunos; 7. a abordagem, o conhecimento e a atitude do professor.

Apesar da inserção do dicionário nos documentos oficiais, os próprios parâmetros curriculares resumem sua aparição em sala a uma ferramenta de consulta pontual, com propósito específico, por exemplo, uma dúvida em relação à ortografia de uma dada unidade lexical, ou em relação ao seu sentido, porém não como um instrumento de constante reflexão sobre a língua. Diante da

Forum lingüístic., Florianópolis, v.17,n.3,p.5073-5087, jul./set. 2020. 
obrigatoriedade em definir qual o melhor dicionário (KRIEGER, 2011), que requer uma análise crítica e avaliativa em consonância com o projeto de ensino, o professor acaba por render-se à lógica comercial ou aos critérios práticos. A esse respeito, até o ano de 2006 os dicionários escolhidos pelo MEC eram considerados inapropriados para alguns ciclos de ensino. Apenas a partir desse ano que a análise dos dicionários submetidos à avaliação passou a adotar critérios rigorosos e teoricamente fundados.

Sendo assim, dentre os itens supracitados propostos por Carstens (1995), a falta de habilidade e a atitude do professor são aspectos que necessitam de maior atenção no contexto escolar brasileiro. O despreparo do mestre frente ao uso das obras lexicográficas em sala de aula resulta na utilização superficial da obra por parte do aluno, no desperdício do potencial informativo da obra, assim como no desenvolvimento da antipatia pelo instrumento por parte do discente e até mesmo na criação/sustentação de mitos e crenças relacionados ao livro. Portanto, torna-se indispensável tanto para o professor quanto para o aluno:

a) entender que o fazer lexicográfico não se resume à compilação de palavras listadas em ordem alfabética;

b) perceber, consequentemente, que um dicionário não é igual ao outro;

c) reconhecer a riqueza linguística e cultural que representa o objeto dicionário.

Em contrapartida, é preciso que o professor, como orientador da formação intelectual do aluno, saiba:

d) identificar os princípios teóricos e metodológicos que conduziram a elaboração da obra;

e) definir a categoria de dicionário mais adequada para o contexto de uso e para o seu projeto de ensino.

A partir desses pressupostos, o professor terá condições de aproveitar o instrumento didático que é o dicionário em sua totalidade. Sobre o papel do docente, Durão e Bolzan (2011, p. 326) enfatizam que "[...] professores mais preparados podem ser agentes melhor qualificados para a transformação do meio escolar em conjunto com a consideração dos conhecimentos já dominados pelos alunos".

Baseando-nos em Ciro (2007), acrescentamos que o domínio do dicionário como ferramenta de ensino potencializa a elaboração de estratégias de ensino de língua, sobretudo no que diz respeito à apropriação do léxico. Becerra Hiraldo (2012) afirma que os exercícios envolvendo o trabalho com o léxico precisam estar sustentados em uma base teórica sólida. Por isso, é preciso que o professor realize uma autoavaliação sobre seus conhecimentos lexicológicos e lexicográficos.

Por outro lado, no que tange ao interesse por parte do discente, Nadin e Fuentes Morán (2015) argumentam:

[... el uso correcto de cualquier herramienta exige una cierta conciencia de para qué sirve, cómo funciona, qué se puede esperar de ella, etc. [...] El conocimiento más o menos profundo de esta forma de conglomerado textual (Wiegand y Fuentes Morán, 2009) depende generalmente de la experiencia del usuario, en muchos casos iniciada en el ámbito escolar, de su formación, de sus intereses, y de las más variadas circunstancias individuales. (NADIN, FUENTES MORÁN, 2015, p.2)

É evidente, portanto, que o sucesso da consulta da obra depende de uma iniciativa bilateral, em que o professor incita a curiosidade do aluno e a orienta; por seu turno, o aluno age de forma autônoma e consciente durante a pesquisa.

Uma vez tendo assumido o aluno o papel de personagem principal no processo de ensino-aprendizagem, cabe também a ele refletir sobre os significados das unidades lexicais, descrevê-los, contrapô-los em diferentes situações comunicativas, além de confrontar a sua intuição com o sentido dicionarizado, de modo a reconstruir a sua identidade e desenvolver o senso crítico sobre a evolução da língua e sobre as relações de poder por ela instauradas. Definitivamente, todo o processo de elaboração de tais obras segue uma ideologia, uma visão de mundo e um objetivo. Logo, é preciso identificá-los e assumir uma posição em relação a eles. O professor, nesse processo, atua como o mediador desse descobrimento.

Nesse sentido, torna-se fundamental o contato direto do profissional em Lexicografia com o público por meio do diálogo com professores e alunos, de forma a evitar frustrações de ambas as partes com a obra, por um lado, e desenvolver um olhar crítico sobre a mesma, por outro, que desmistifique as crenças (PONTES; SANTIAGO, 2009) ainda arraigadas na sociedade brasileira, como por exemplo a atemporalidade, a completude, a neutralidade e a qualidade de representante universal de uma língua (PONTES, 2009, 2014). 


\section{ANÁLISE DO MATERIAL DIDÁTICO DESTINADO AO ENSINO MÉDIO OFERECIDO PELAS ESCOLAS PÚBLICAS DO ESTADO DE SÃO PAULO.}

O Caderno do Aluno - Língua Portuguesa e Literatura (SÃO PAULO, 2014) tem como base o Currículo Oficial do Estado de São Paulo e objetiva articular o currículo com o ambiente em sala de aula. Cada caderno é destinado a uma série do Ensino Médio e é dividido em dois volumes. O educador, por sua parte, conta com o Caderno do Professor (SÃO PAULO, 2014), que traz orientações didático-pedagógicas para o desenvolvimento eficiente das competências e habilidades exigidas do alunado nesse período escolar. O material em apreço é fruto do esforço de implantar o Currículo Oficial e articular os objetivos educacionais visados no Estado de São Paulo.

No que tange à Matriz de Avaliação Processual - MAP (SÃO PAULO, 2016), especificamente a versão lançada pela mesma secretaria em 2016, seu propósito é monitorar a qualidade do aprendizado das competências e habilidades em foco em cada etapa escolar. Ao adotar uma perspectiva longitudinal de aprendizagem, ilustra o conteúdo de forma progressiva, pois o desenvolvimento do conhecimento do aluno é visto como um processo. Assim, em cada ano, para cada bimestre, foca-se na Matriz, um conjunto de conteúdos a serem trabalhados pelo professor, com o auxílio do material de apoio, em uma dada modalidade organizativa e que buscará uma determinada avaliação processual/habilidade. As figuras 1 e 2 ilustram a proposta para o primeiro bimestre da primeira série do EM.

\begin{tabular}{|c|c|c|}
\hline \multicolumn{3}{|l|}{$1^{\circ}$ Série $-1^{\circ}$ bimestre } \\
\hline \multirow{2}{*}{ Conteúdos } & Situações de Aprendizagem & \multirow{2}{*}{ Avaliação Processual/Habilidades } \\
\hline & Competência/Habilidade & \\
\hline 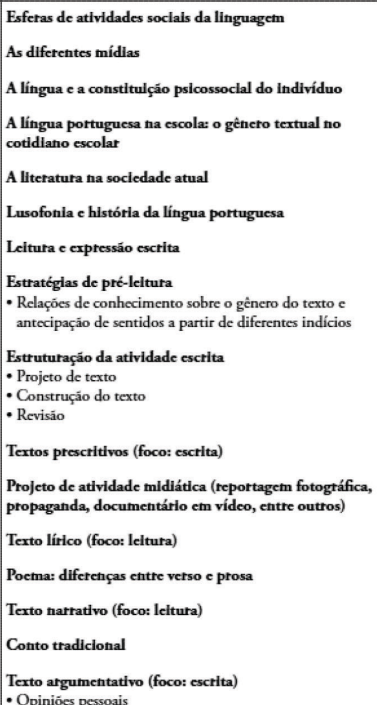 & 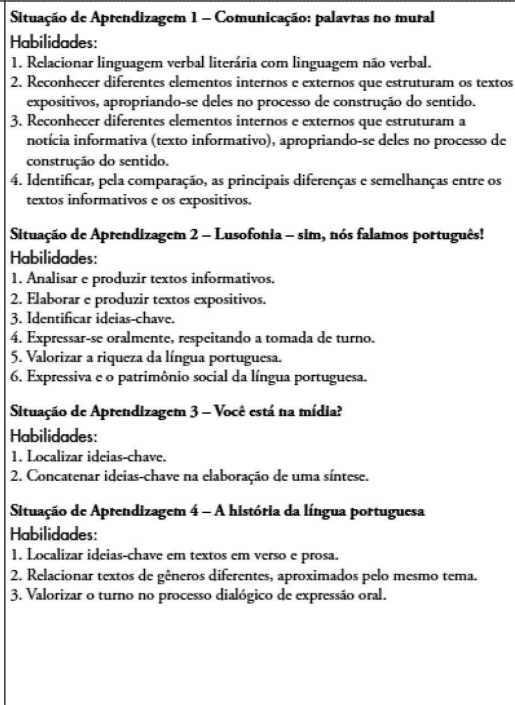 & 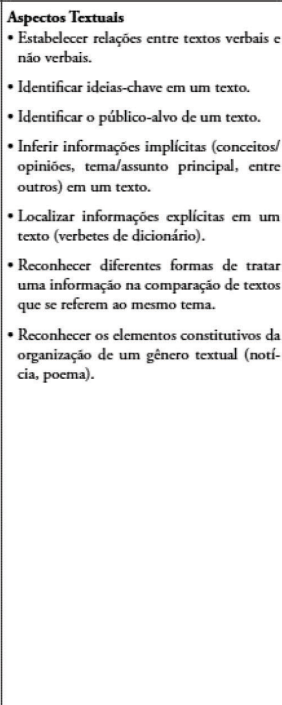 \\
\hline
\end{tabular}

Figura 1: Conteúdos da MAP

Fonte: Retirado de MAP (2016, p.46) 


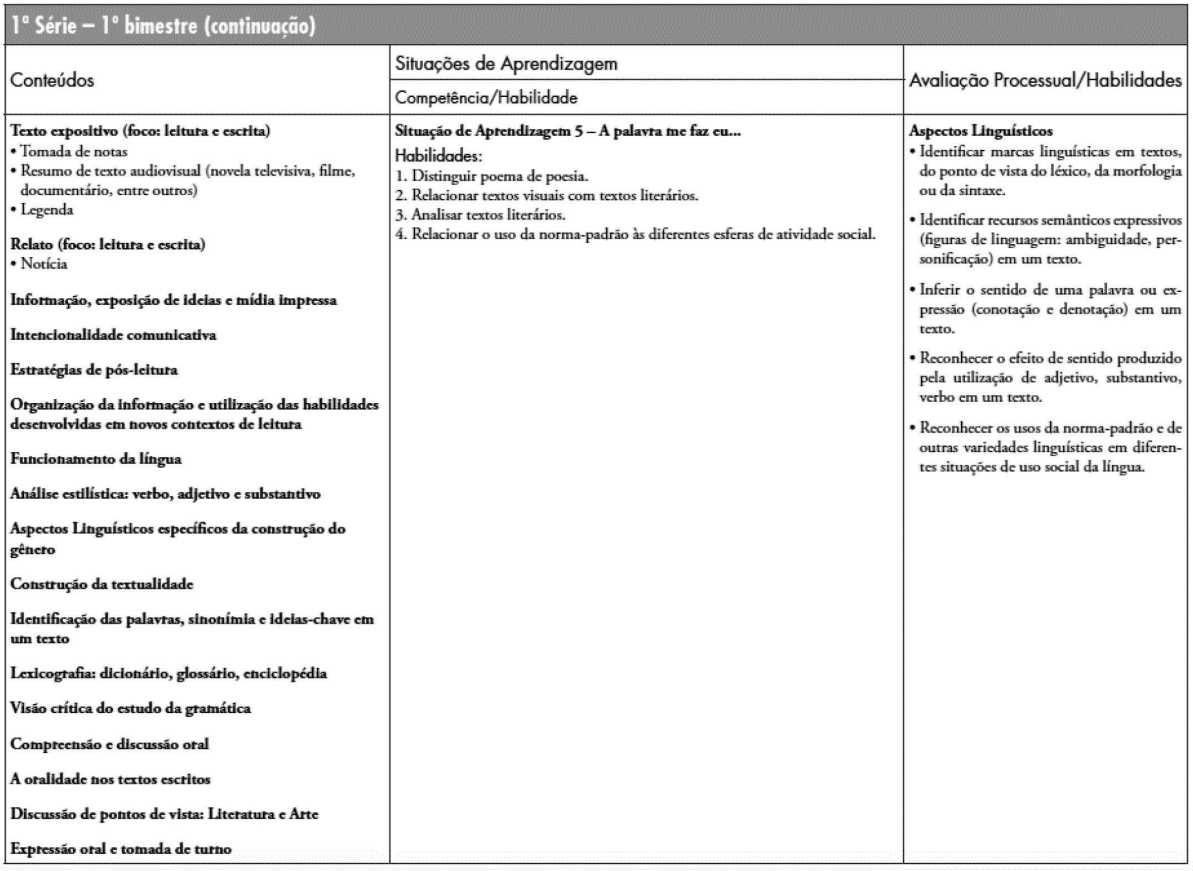

Figura 2: Conteúdos da MAP

Fonte: Retirado de MAP (2016, p.47 - continuação)

Verifica-se, claramente, a expectativa quanto ao uso do dicionário como um objeto didático e necessário em sala de aula. É evidente, ainda, que se espera que um aluno da primeira série do EM tenha contato com aspectos lexicográficos necessários ao pleno uso do dicionário, especificamente, localizar informações explícitas a respeito de uma unidade lexical, seja ela utilizada nos discursos cotidianos ou pertencente a um domínio específico do saber científico-tecnológico, em verbetes de dicionários. Contudo, nenhuma atenção concreta é dada ao direcionamento da manipulação de dicionários, glossários e enciclopédias. Antes, no Caderno do Professor apenas encontramos menções a tais obras de referência nos roteiros de cada unidade a ser trabalhada, como representado na figura que segue, referente à Situação de aprendizagem 1 "Comunicação: palavras no mural", do Caderno 1, Vol. 1, da 1 a série do EM.

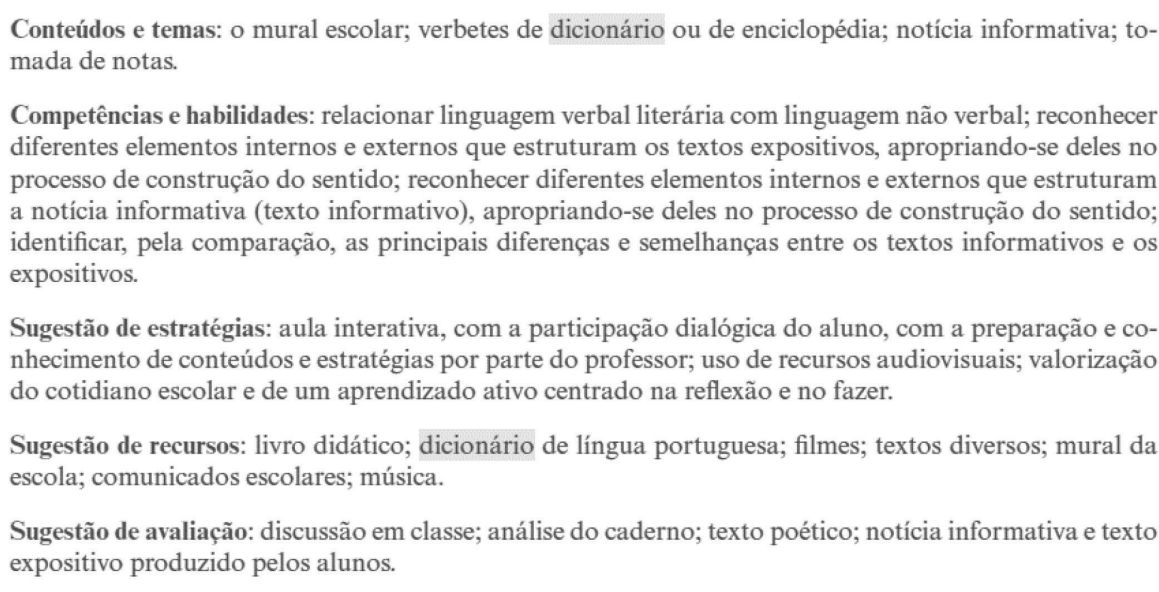

Sugestão de estratégias: aula interativa, com a participação dialógica do aluno, com a preparação e conhecimento de conteúdos e estratégias por parte do professor; uso de recursos audiovisuais; valorização do cotidiano escolar e de um aprendizado ativo centrado na reflexão e no fazer.

Sugestão de recursos: livro didático; dicionário de língua portuguesa; filmes; textos diversos; mural da escola; comunicados escolares; música.

Sugestão de avaliação: discussão em classe; análise do caderno; texto poético; notícia informativa e texto expositivo produzido pelos alunos.

Figura 3: Roteiro para o professor

Fonte: Retirado do Caderno do Professor para o $1^{\circ}$ ano do EM (2014-2017, p.8)

No roteiro para a aplicação da Situação de aprendizagem 1 "Comunicação: palavras no mural", do Caderno 1, Vol. 1, da 1 a série do EM, sugere-se que o professor utilize verbetes de dicionários ou enciclopédias para apresentar tal gênero ao aluno e incentivar determinado uso no cotidiano escolar. No entanto, como discutido anteriormente, o despreparo do docente quanto aos 
pressupostos lexicográficos é um empecilho para o uso de obras de referência em sala. Aliado a tal fator, a falta de tempo hábil, tanto para o preparo quanto para a aplicação de atividades extras, é outro impedidor do uso de obras lexicográficas em sala.

Por conseguinte, o professor limita-se às atividades presentes no Caderno do Aluno, tais como a ilustrada a seguir:

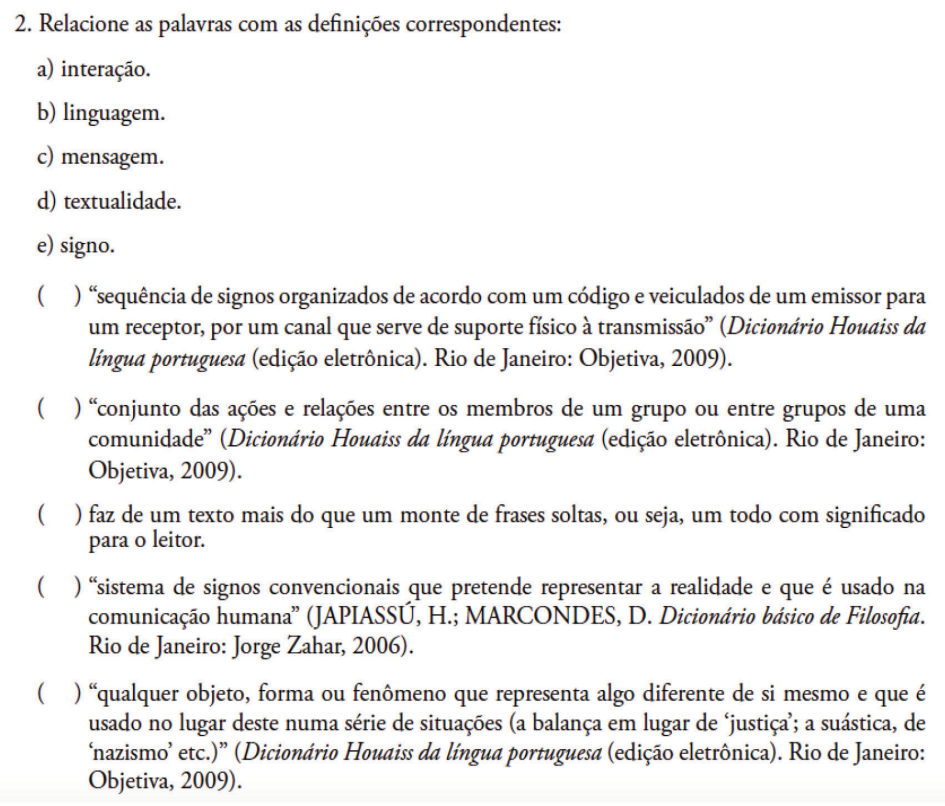

Figura 4: Atividade com uso de dicionário

Fonte: Retirado do Caderno do Aluno do $1^{\circ}$ ano do EM (2014-2017, p.8)

De um modo geral, a proposta nesse exercício é o trabalho com a definição lexicográfica. É preciso enfatizar, contudo, que as unidades lexicais abordadas pertencem a uma terminologia específica, cuja particularidade está representada na definição, fato que dificulta o desenvolvimento do exercício por parte do aprendiz. Definitivamente, trata-se de uma atividade que pouco contribui para a integração do dicionário no cotidiano do aluno.

Em suma, visto que se trata de uma unidade que tem como tema o trabalho lexical para a comunicação, para a inserção do objeto dicionário na sequência didática, é fundamental que o professor:

a) tenha consciência de que o dicionário, ao lado da gramática, é um pilar do saber metalinguístico de uma língua natural;

b) tenha conhecimento teórico aprofundado sobre as características do léxico das línguas naturais;

c) esteja familiarizado com as funções e as características dos dicionários.

Consequentemente, ele estará preparado para orientar o aluno a:

a) identificar a riqueza do léxico da Língua Portuguesa;

b) reconhecer processos semânticos utilizados em determinados textos ou contextos;

c) diferenciar as características das unidades lexicais utilizadas nos discursos cotidianos daquelas pertencentes a determinados domínios do saber;

d) familiarizar-se com as características e funções dos diferentes dicionários, transformando as informações contidas nessas obras em conhecimento linguístico.

A Situação de Aprendizagem 2, intitulada "Lusofonia - Sim, nós falamos português!", tem como objetivo provocar o reconhecimento, por parte do aluno, da propriedade da língua, especificamente a portuguesa, como identificadora de povos e culturas distintos. O tema da variação linguística, portanto, dialoga com o dicionário na medida em que este descreve os (não) usos 
de uma dada unidade lexical, além dos diferentes sentidos a ela atribuídos por comunidades distintas. Faz-se referência ao uso do dicionário em apenas dois exercícios e unicamente no material do professor. Em ambas as atividades, o dicionário é tratado como um mero tira-dúvidas quanto ao sentido das palavras. Não há, em nenhum momento, indicações no material em análise, seja no destinado ao aluno, seja no do professor, de possibilidades de aproveitamento do dicionário que contribuam para a compreensão do tema.

A Situação de Aprendizagem 3, intitulada "Você está na Mídia?", faz menção ao dicionário durante a abordagem de processos semânticos da linguagem. Também nessa unidade há apenas dois exercícios que estimulam o uso de obras de referência. O primeiro retoma a relação de metonímia entre mídia e televisão, fazendo uso, para tanto, do verbete mídia retirado do Dicionário Houaiss da Língua Portuguesa, como ilustrado a seguir:

1. Acompanhe a música selecionada pelo professor. Anote a letra no caderno.

Professor, como dissemos, tendo em vista que a discussão será direcionada para mídia e televisão, escolha uma letra de música propícia a esse encaminhamento.

2. Veja o que um dicionário explica sobre o termo mídia:
Mídia: S. f. 1 todo suporte de difusão da informação que constitui um meio intermediário de expressão capaz de transmitir mensagens; o conjunto dos meios de comunicação social de massas [Abrangem esses meios o rádio, o cinema, a televisão, a imprensa, os satélites de comunicações, os meios eletrônicos e telemáticos de comunicação etc.].

Dicionário Houaiss da língua portuguesd (edição eletrônica). Rio de Janeiro: Objetiva, 2009.

Figura 5: Atividade com base em verbete de dicionário

Fonte: Retirado do Caderno do Professor para o $1^{\circ}$ ano do EM (2014-2017, p.26)

O segundo exercício retoma a relação de sinonímia para enfatizar o efeito das escolhas lexicais no nível de formalidade dos discursos. Vejamos:

a) Que relação existe entre mídia e televisão?

Tendo em vista a definição, é possivel dizer que a televisão é uma parte da mídia.

b) Observe: A televisão está me deixando muito burro.

O dicionário nos informa que um dos sinônimos de burro é obtuso. Que diferença de sentido faria para a frase se, em vez do adjetivo burro, o autor tivesse usado obtuso?

Há diversas possibilidades de resposta que giram em torno do

fato de que a frase teria ficado menos informal.

Figura 6: : Atividade com base em verbete de dicionário

Fonte: Retirado do Caderno do Professor para o $1^{\circ}$ ano do EM (2014-2017, p.27)

Em ambas as situações, cabe ao professor identificar os fenômenos, defini-los e propor formas sistemáticas de análise.

Na Situação de Aprendizagem 7, intitulada “Exposição de fotojornalismo 'O sabor da língua portuguesa”, há a proposta de construção de texto coletivo, cabendo ao dicionário o papel de diluir dúvidas de grafia e significado.

Já na Situação de Aprendizagem 8, intitulada "Divulgando a exposição", propõe-se que o aluno procure no dicionário a definição de folheto que se enquadra no tema, como ilustrado a seguir: 
2. Procure no dicionário a definição de folheto que melhor se relaciona com o tema que estamos estudando. Transcreva-a no caderno. Com essa atividade, é possível perceber se o aluno está compreendendo a proposta com o folheto e, se necessário, fazer intervenções para corrigir concepções equivocadas ou resolver dúvidas.

Figura 7: Atividade para uso do dicionário

Fonte: Retirado do Caderno do Professor para o $1^{\circ}$ ano do EM (2014-2017,p.82)

A Situação de Aprendizagem 9, intitulada “Quando as palavras resolvem fazer arte!", retoma a reflexão sobre acepções e sentido por intermédio do vocabulário utilizado em um poema de Camões:

Julga-me a gente toda por perdido,
Vendo-me tão entregue a meu cuidado,
Andar sempre dos homens apartado
E dos tratos humanos esquecido.

Qual das acepções a seguir, retiradas do dicionário, apresenta melhor o sentido do termo cuidado nessa estrofe?

a) bem-feito.

b) previsto.

c) dedicação.

d) trabalho.

e) calculado.

Figura 8: Atividade que retoma os conceitos de acepções e sentido

Fonte: Retirado do Caderno do Professor para o $1^{\circ}$ ano do EM (2014-2017, p.89)

Cabe ao aluno identificar a palavra que melhor se encaixa no poema. Importa ressaltar que não há referência ao dicionário utilizado, tampouco ulteriores direcionamentos ao professor. Sendo assim, é de sua responsabilidade entender e diferenciar acepção de sentido, situação que se torna problemática diante da falta de cuidado com a elaboração da atividade.

O último exercício que exige o uso do dicionário está presente na Situação de Aprendizagem 10, intitulada “Um, dois, três... Ação!”, retomando o uso e os significados das palavras ao longo do tempo. Vejamos:

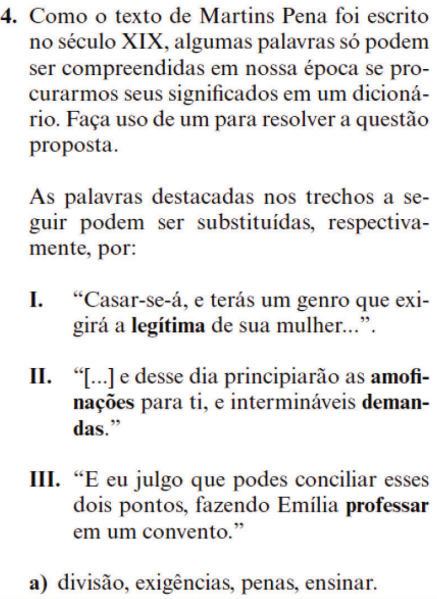

4. Como o texto de Martins Pena foi escrito no século XIX, algumas palavras só podem ser compreendidas em nossa época se procurarmos seus significados em um dicionário. Faça uso de um para resolver a questão proposta.

As palavras destacadas nos trechos a seguir podem ser substituídas, respectivamente, por:

I. "Casar-se-á, e terás um genro que exigirá a legítima de sua mulher...”.

II. "[...] e desse dia principiarão as amofinações para ti, e intermináveis demandas."

III. "E eu julgo que podes conciliar esses dois pontos, fazendo Emilia professar em um convento."

a) divisão, exigências, penas, ensinar.

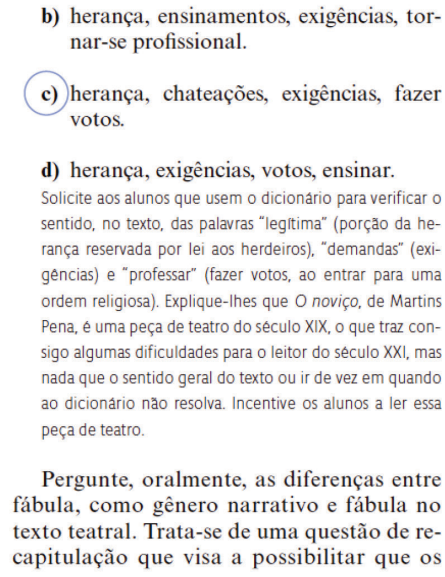

Pergunte, oralmente, as diferenças entre fábula, como gênero narrativo e fábula no texto teatral. Trata-se de uma questão de recapitulação que visa a possibilitar que os

Figura 9: Atividade para compreensão dos sentidos

Fonte: Retirado do Caderno do Professor para o $1^{\circ}$ ano do EM (2014-2017, p.112) 
O exercício mostra-se problemático na medida em que contribui para a concepção errônea de que todo dicionário irá elencar todas as palavras de uma língua, assim como todos os sentidos a elas atribuídos. Não há indicação de obra de referência, e cabe especificar que os dicionários elaborados segundo os pressupostos lexicográficos seguem uma metodologia rigorosa que inclui a definição de um corpus que servirá como base para o delineamento da macroestrutura, bem como das acepções e definições das entradas. $\mathrm{O}$ Dicionário Unesp do português contemporâneo, por exemplo, uma das obras que integram o conjunto de dicionários do Tipo 4, foi elaborado tomando-se por base um "[...] corpus de cerca de 90 milhões de itens lexicais em textos escritos no Brasil a partir de 1950" (BORBA, 2004, p. VII).

Tomemos como exemplo a palavra legítima que, nesse caso, significa uma porção da herança reservada por lei aos herdeiros. $\mathrm{O}$ Dicionário Unesp do português contemporâneo não traz em sua nomenclatura o item legítima. Em legítimo não consta definição cabível nesse contexto e também não há referência a esse sentido. Sendo assim, cabe a seguinte questão: Caso o aluno faça uso do dicionário indicado pelo PNLD: dicionários, cujas obras deveriam estar acessíveis em sala, saberia o professor mediar uma situação em que as informações necessárias para a resolução da atividade não constem na obra?

No segundo volume do Caderno do Aluno para o $1^{\circ}$ ano, o incentivo ao uso do dicionário acontece em apenas três exercícios, um deles na Situação de Aprendizagem 3 - "Instalação poética", e outros dois na Situação de Aprendizagem 6 - "O estilo que critica o mundo”. Trata-se de atividades de compreensão de textos poéticos que recorrem às dúvidas de significado sobre determinadas palavras.

Já no primeiro volume do Caderno do Aluno para o $2^{\circ}$ ano a situação regride, pois o aluno é estimulado ao uso de obras de referência apenas em duas atividades. Em ambas, ele é confrontado com um verbete e, a partir das informações nele constantes, deverá atribuir o sentido adequado de uma dada palavra que ocorre em um determinado texto literário.

No segundo volume do Caderno do Aluno para o $2^{\circ}$ ano repete-se o padrão adotado nos cadernos anteriores. De modo geral, é recorrente o enunciado "procure seu sentido no dicionário". Obviamente, sobretudo devido à falta de tempo hábil em sala de aula, é pouco provável que o aluno recorra à obra.

Assim como nos outros volumes, o primeiro volume do Caderno do Aluno para o $3^{\circ}$ ano faz menção direta ao dicionário Houaiss ao reproduzir o verbete pau de arara, como ilustrado a seguir:

3. Observe que o dicionário nos fornece diversas acepções para o termo pau de arara.

1. Suporte de madeira no qual os sertanejos conduzem araras, papagaios e outras aves trepadoras, para vender. 2. Instrumento de tortura que consiste num pau roliço em que o torturado é pendurado pelos joelhos e cotovelos flexionados; cambau. 3. Caminhão que transporta retirantes nordestinos. 4. Derivação: por extensão de sentido (da acp. 3). Nordestino que migra ger. para o Sudeste do Brasil, viajando em paus de arara. 4.1. Derivação: por extensão de sentido. Uso: pejorativo. Qualquer nordestino.

Dicionário Houaiss da lingua portuguesa (edição eletrônica). Rio de Janeiro: Objetiva, 2009.

Figura 10: Verbete retirado do Dicionário Houaiss

Fonte: Retirado do Caderno do Professor para o $3^{\circ}$ ano do EM (2014-2017, p.48)

Entretanto, trata-se de uma informação aleatória, inutilizada nos exercícios e sem maiores orientações para o professor. Ademais, ainda nesse caderno, nas propostas de elaboração de texto, o dicionário é vinculado à norma padrão na medida em que se exige do aluno a consulta às obras de referência para verificar o uso correto das palavras.

Por fim, no segundo volume do Caderno do Aluno para o $3^{\circ}$ ano, repete-se o modelo anteriormente mencionado, em que se pede que o aluno "Encontre no dicionário a acepção (definição) que melhor se adapta ao conceito". 
Isso posto, é evidente que os alunos não dedicarão os esforços necessários para ter familiaridade com as obras de referência. Tampouco a escola contribuirá para criar uma cultura do dicionário, na qual os membros de uma sociedade utilizam efetivamente tais obras como instrumento de apropriação de uma língua. Torna-se evidente, portanto, a urgência da capacitação dos profissionais para que as políticas linguísticas alcancem o sucesso esperado.

\section{CONSIDERAÇÕES FINAIS}

É de comum acordo que o aprendizado do léxico é constante, uma vez que frequentemente adentramos situações comunicativas adversas, que nos exigem esforços para compreender o que está sendo dito, para identificar referentes. Como poderia ser diferente se é o léxico o responsável por categorizar e tornar consistente o conhecimento acumulado por um povo? Logo, estimular a curiosidade do aluno em aprender novas palavras, e inclusive conscientizá-lo a respeito da utilidade em adquirir tal conhecimento, torna-se central.

Por conseguinte, desconstruir a idealização que gira em torno do objeto dicionário é fundamental. Para tanto, por um lado, é preciso familiarizar-se com as etapas metodológicas envolvidas no trabalho lexicográfico, além de conhecer a obra com a qual se lida; por outro, o domínio das características do gênero textual verbete de dicionário traz praticidade à busca. Assim, como etapa basilar do uso do dicionário em sala tem-se a possibilidade de acesso à obra, que deve estar à disposição do aluno diariamente. Talvez esse seja o principal desafio quando se trata da escola pública, onde geralmente os dicionários permanecem trancafiados em bibliotecas inacessíveis.

Ao longo destas páginas, enfatizamos o caráter didático do dicionário no que tange à apropriação da língua materna. Como indicado nas análises, apesar dos esforços tanto por parte do Governo Federal quanto do Estadual para nortear a aprendizagem, efetivados por meio dos Parâmetros Curriculares Nacionais e do Programa Nacional do Livro Didático, por um lado, e pelo Currículo Oficial do Estado de São Paulo, por outro, os efeitos ainda estão muito abaixo do esperado. A realidade em sala de aula demonstra o desencorajamento causado por professores mal-preparados quanto ao correto direcionamento da manipulação de dicionários, glossários e enciclopédias. Embora constate-se o estímulo no material fornecido pela Secretaria de Educação do Estado de São Paulo, poucas são as atividades que exigem do aluno tal prática.

Visto que nosso foco esteve voltado ao exame do material didático distribuído pelo Estado de São Paulo, privamo-nos de maiores aprofundamentos sobre o perfil do sujeito-aluno, sobre o ambiente escolar e até mesmo sobre os dicionários de Tipo 4. Contudo, de maneira alguma consideramos tais temas irrelevantes. Antes, este trabalho representa apenas um passo nessa trilha de pesquisas.

\section{REFERÊNCIAS}

AUROUX, S. A revolução tecnológica da gramatização. Trad. Eni Puccinelli Orlandi. Campinas: Editora da Unicamp, 1992.

BAGNO, M.; RANGEL, E.O. Tarefas da educação linguística no Brasil. Revista Brasileira de Linguística Aplicada, v. 5, n. 1, p. 63-81, 2005.

BÉJOINT, H. The Lexicography of English: from origins to present. New York: Oxford University Press, 2010.

BECERRA HIRALDO, J.M. Teoría de la práctica lexicológica. Porta Linguarum, n. 18, p. 43-59, junio 2012.

BRASIL. MINISTÉRIO DA EDUCAÇÃO. SECRETARIA DE EDUCAÇÃO BÁSICA. Com direito à palavra: dicionários em sala de aula. Elaboração Egon Rangel. Brasília: Ministério da Educação, Secretaria de Educação Básica, 2012.

Forum lingüístic., Florianópolis, v.17,n.3,p.5073-5087,jul./set. 2020 
BRASIL. MINISTÉRIO DA EDUCAÇÃO. SECRETARIA DE EDUCAÇÃO BÁSICA. Com direito à palavra: dicionários em sala de aula. Elaboração Egon Rangel. Brasília: Ministério da Educação, Secretaria de Educação Básica, 2006.

CARSTENS, A. Language teaching and dictionary use: an overview. Lexikos, AFRILEX-reeks/series, 5B, p. 105-116, 1995.

CASTILHO, A.T. Políticas lingüísticas no Brasil: o caso do portugues brasileiro. Lexis XXV, n. 1-2, p. 271-297, 2001.

CIRO, L.A. El diccionario como objeto de estudio y herramienta didáctica en la enseñanza de la lengua. EL ÁGORA USB, v. 7, n. 1, p. 57-64, enero-junio 2007.

COROA, M. L. Para que serve um dicionário? In: CARVALHO, O.; BAGNO, M. (org.). Dicionários escolares: políticas, formas e usos. São Paulo: Parábola, 2011.p. 61-72.

DURÃO, A. B. A. B.; BOLZAN, R. M. A formação docente em lexicografia e a realidade sobre o trabalho com dicionários em sala de aula. Eutomia, Recife, v. 4, p. 323-345, 2011.

FUERTES-OLIVERA, P. A.; TARP, S. La teoría funcional de la lexicografía y sus consecuencias para los diccionarios de economía del español. Revista de Lexicografía, A Coruña, n. 14, p. 75-95, 2008.

GUMARÃES, E. Política de línguas na América Latina. Relatos, HIL/UNICAMP, n. 7, p. 5-11, jun. 2001.

JACKSON, H. Lexicography: an Introduction. London: Routledge, 2002.

KRIEGER, M.G. Dicionários escolares e ensino de língua materna. Estudos Linguísticos, São Paulo, v. 41, n. 1, p. 169-180, 2012.

KRIEGER, M.G. Questões de lexicografia pedagógica. In: XATARA, C.; BEVILACQUA, C. R.; HUMBLÉ, P. R. M. (org.). Dicionários na teoria e na prática: como e para quem são feitos. São Paulo: Parábola Editorial, 2011. p. 103-113.

KRIEGER, M.G. Dicionários para o ensino de língua materna: princípios e critérios de escolha. Revista Língua e Literatura, v. 6-7, n. 10-11, p.101-112, 2004-2005.

MADEIRA, F. Crenças de professores de português sobre o papel da gramática no ensino de língua portuguesa. Linguagem e ensino, v. 8, n. 2, p. 17-38, 2005.

NADIN, O. L. ; FUENTES MORÁN, M. T. Las instrucciones de uso en diccionarios bilingües de español para escolares brasileños. Suplemento Signos ELE, v. 1, p. 1-13, 2015.

OliveIRA, G. M. de. Políticas linguísticas como políticas públicas. 2013. Disponível em: http://e-ipol.org/wpcontent/uploads/2013/06Politicas_linguisticas_e_Politicas_publicas.pdf. Acesso em: 20 ago. 2019.

ORLANDI, E.P. Ética e política linguística. línguas e instrumentos linguísticos. Campinas: Pontes, 1998.

PONTES, A.L. O dicionário escolar como ferramenta pedagógica. In: VIDAL, R. M. B.; BERNARDINO, R. A. S.; PONTES, A. L. (org.). Produção e ensino de texto em diferentes perspectivas. Mossoró: Edições UERN, 2014. p. 12-25.

PONTES, A.L. Dicionário para uso escolar: o que é e como se lê. Fortaleza: EDUECE, 2009. 
PONTES, A.L.; SANTIAGO, M. S. Crenças de professores sobre o papel do dicionário no ensino de língua portuguesa. In: COSTA DOS SANTOS, F. J. (org.). Letras plurais: crenças e metodologias do ensino de línguas. Rio de Janeiro: Câmara Brasileira de Jovens Escritores, 2009.p. 105-123.

SÃO PAULO (Estado). Secretaria de Educação. Caderno do Aluno. Lingua portuguesa e literatura: ensino médio. 1a série. São Paulo: SEE, 2014. $2 \mathrm{v}$.

SÃO PAULO (Estado). Caderno do Aluno. Língua portuguesa e literatura: ensino médio. 2a série. São Paulo: SEE, 2014. 2 v.

SÃO PAULO (Estado). Caderno do Aluno. Língua portuguesa e literatura: ensino médio. 3a série. São Paulo: SEE, 2014. 2 v.

SÃO PAULO (Estado). Caderno do Professor. Língua portuguesa e literatura: ensino médio. 1a série. São Paulo: SEE, 2014. 2 v.

SÃO PAULO (Estado). Caderno do Professor. Língua portuguesa e literatura: ensino médio. 2a série. São Paulo: SEE, 2014. 2 v.

SÃO PAULO (Estado). Caderno do Professor. Língua portuguesa e literatura: ensino médio. 3a série. São Paulo: SEE, 2014.2 v.

SÃO PAULO (Estado). Matriz de avaliação processual: língua portuguesa, linguagens. São Paulo: SEE, 2016.

SANTOS, H. L. G.; SOUSA, A. G. F. PNLD e dicionários escolares: impactos pedagógicos e acadêmicos. In: XXII Semana de Educação, 2015, Fortaleza. Anais ... Fortaleza, 2015.

TORQUATO, C.P. Políticas linguísticas, linguagem e interação social. Revista escrita, n. 11, p. 1-28, 2010.

\section{(๑) $\circledast \circledast$}

